\title{
Dual TNFa-Induced Effects on NRF2 Mediated Antioxidant Defence in Astrocyte-Rich Cultures: Role of Protein Kinase Activation
}

\author{
Fernando Correa, \\ Department of Medical Biochemistry and Cell Biology, Institute of Biomedicine, University of \\ Gothenburg, PO BOX 420, 40530 Göteborg, Sweden
}

Carina Mallard,

Department of Physiology, Institute of Neuroscience and Physiology, University of Gothenburg, Göteborg, Sweden

Michael Nilsson, and

Institute of Neuroscience and Physiology, CBR, University of Gothenburg, Göteborg, Sweden

Mats Sandberg

Department of Medical Biochemistry and Cell Biology, Institute of Biomedicine, University of Gothenburg, PO BOX 420, 40530 Göteborg, Sweden

Fernando Correa: fernando.correa@medkem.gu.se

\section{Abstract}

Tumor necrosis factor- $a(\mathrm{TNF} a)$ is a pleiotropic molecule that can have both protective and detrimental effects in neurodegeneration. Here we have investigated the temporal effects of TNF $a$ on the inducible Nrf2 system in astrocyte-rich cultures by determination of glutathione (GSH) levels, $\gamma$ glutamylcysteine ligase ( $\gamma \mathrm{GCL}$ ) activity, the protein levels of Nrf2, Keap1, the catalytic and modulatory subunit of $\gamma \mathrm{GCL}(\gamma \mathrm{GCL}-\mathrm{C}$ and $\gamma \mathrm{GCL}-\mathrm{M}$ respectively). Astrocyte-rich cultures were exposed for 24 or $72 \mathrm{~h}$ to different concentrations of TNF $a$. Acute exposure ( $24 \mathrm{~h}$ ) of astrocyte-rich cultures to $10 \mathrm{ng} / \mathrm{mL}$ of TNF $a$ increased GSH, $\gamma \mathrm{GCL}$ activity, the protein levels of 2 GCL-M, 2 GCL-C and Nrf2 in parallel with decreased levels of Keap1. Antioxidant responsive element (ARE)-mediated transcription was blocked by inhibitors of ERK1/2, JNK and Akt whereas inactivation of $\mathrm{p} 38$ and GSK $3 \beta$ further enhanced transcription. In contrast treatment with TNF $a$ for $72 \mathrm{~h}$ decreased components of the Nrf2 system in parallel with an increase of Keap1. Stimulation of the Nrf2 system by $t \mathrm{BHQ}$ was intact after $24 \mathrm{~h}$ but blocked after $72 \mathrm{~h}$ treatment with TNF $a$. This down-regulation after $72 \mathrm{~h}$ correlated with activation of p38 MAPK and GSK3 $\beta$, since inhibition of these signalling pathways reversed this effect. The upregulation of the Nrf2 system by TNF $a$ ( $24 \mathrm{~h}$ treatment) protected the cells from oxidative stress through elevated $\gamma \mathrm{GCL}$ activity whereas the down-regulation ( $72 \mathrm{~h}$ treatment) caused pronounced oxidative toxicity. One of the important implications of the results is that in a situation where Nrf2 is decreased, such as in Alzheimer's disease, the effect of TNF $a$ is detrimental.

(C) Springer Science+Business Media, LLC 2012

Correspondence to: Fernando Correa, fernando. correa@medkem.gu. se.

Electronic supplementary material The online version of this article (doi:10.1007/s11064-012-0878-y) contains supplementary material, which is available to authorized users. 


\section{Keywords}

Neuroinflammation; Nrf2; Antioxidant system; TNFa; Glutathione

\section{Introduction}

Cytokines such as tumor necrosis factor $a(\mathrm{TNF} a)$ are elevated in the brain in a number of acute and chronic neurodegenerative diseases [31]. The functional significance of these changes is not fully clear and TNF $a$ can exert both protective and detrimental effects on brain cells. The protective effects include increased levels of the anti-oxidant glutathione (GSH) [59], increased levels of the anti-apoptotic protein Bcl-2 [55], maintained $\mathrm{Ca}^{2+}$ homeostasis [5] and elevated protective enzymes such as MnSOD [2]. However, detrimental effects such as decreased anti-oxidant defense and oxidative stress that initiate apoptosis or necrosis have also been described [34]. Lowered levels of growth factors by TNF $a$, for example nerve growth factors, have also been reported [14]. The circumstances that determine whether TNF $a$ have toxic or protective effects are at large unknown, but it is likely that the concentration of TNF $a$, the chemical environment (neurotrophic factors and other cytokines), the receptor distribution in different brain areas and the duration of elevated TNF $a$ levels are important $[13,38]$. For example it has been shown that chronic treatment with low levels of TNF $a$ in the substantia nigra by microinjection of an adenoviral vector expressing TNF $a$ causes neuronal cell death after 14 days but not after 7 days [9], favoring that a temporal aspect is important in TNF $a$ effects.

Astrocytes constitute the main support cell for neurons [1]. This support includes shuttling of glutathione (GSH) to the extracellular space, breakdown of GSH and neuronal uptake of cysteine, which leads to elevated neuronal GSH levels [11]. This antioxidant system can be induced to increase astroglial and neuronal GSH concentrations by the transcription factor Nrf2 [50]. Interestingly it is sufficient to overexpress Nrf2 levels in astrocytes to protect neurons in animal models of neurodegeneration [56]. Reduced levels of Nrf2 makes the astroglial cells more vulnerable to oxidative stress [6], and reduced astroglial support sensitizes neurons to normally non-toxic insults [50]. Deletion of Nrf2 makes the animals over-sensitive to oxidative stress and they also develop white matter damage and retinopathy spontaneously [18, 19, 64]. Interestingly, brains from Alzheimer patients have low levels of Nrf2 in hippocampal astrocytes [41] indicating poor astroglial support in this disease, at least in the hippocampus. The reason for this decrease is at present not known but one possibility is inflammation-induced down-regulation of Nrf2 function, i.e. soluble effectors such as cytokines secreted by activated microglia [6].

TNF $a$ treatment has earlier shown to elevate MnSOD in astrocytes and protect astrocytes from 3-nitropropionic acid induced superoxide accumulation and loss of mitochondrial transmembrane potential [2]. Likewise TNF $a$ increased neuroprotective BDNF synthesis in astrocytes most likely via activation of ERK1/2 [44]. Long term incubation (72 h) of astrocytes with TNF $a(30 \mathrm{ng} / \mathrm{ml})$ induced $\gamma$-glutamyl transpeptidase [43] whereas a depletion of GSH was observed rapidly after adding TNFa $(50 \mathrm{ng} / \mathrm{ml})$ to the culture medium [51]. TNF $a$ can also change the cytokine profile of the astrocyte. It has, for example, been demonstrated that TNF $a$ can lead to induction of other cytokines such as IL-6 [46]. TNF $a$ can also elevate HO-1 expression in astroglia [32]. As expression of HO-1 is partly regulated by Nrf2 this effect implies activation of Nrf2 by TNF $a$.

We have shown that astrocyte-rich cultures treated with medium from LPS-activated microglia can either up-regulate or down-regulate the astrocytic anti-oxidant defense via the transcription factor Nrf2 [6]. The major determinants on the astrocyte anti-oxidant defense 
were the original concentration of LPS used to activate microglia and the time to which the astrocyte-rich culture was subjected to the medium from activated microglia. TNF $a$ is a major cytokine released by activated microglia, is increased in CSF of patients suffering from Alzheimer's disease [21] and systemic TNF $a$, derived from peripheral inflammation, could possibly enter the brain and induce direct effects on brain cells [38]. Here we subjected astrocyte-rich cultures to TNF $a$, and determined the effects on the Nrf2 system and the possible signaling pathways involved.

\section{Materials and Methods}

\section{Reagents}

Lithium chloride ( $\mathrm{LiCl}$ ), buthionine sulfoxide (BSO), $t \mathrm{BHQ}, \mathrm{GSH}$, cysteine, glutamic acid, 5-sulfosalicylic acid (5-SSA), naphthalene-2,3-dicarboxaldehyde (NDA) and hydrogen peroxide $\left(\mathrm{H}_{2} \mathrm{O}_{2}\right)$ were from Sigma (Stockholm, Sweden). U0126 was from Cell Signaling Technology (Beverly, USA). SP600125, SB203085 and Ly294002 were from Calbiochem (Solna, Sweden). Dulbecco's modified Eagle medium, poly-D-lysine, foetal bovine serum (FBS) and penicillin/streptomycin solution were from Gibco/Invitrogen (Merelbeke, Belgium). Other common reagents were purchased from standard suppliers.

\section{Ethics Statement}

All experiments were carried out in accordance with institutional (ethical approval number 395-2008 issued by the Animal Ethical Committee of Gothenburg) and national guidelines for the care and use of experimental animals and the European Communities Council Directive of 24 November 1986 (86/609/EEC).

\section{Astrocyte-Rich Primary Cultures and Treatments}

Cortical astrocyte-rich primary cultures were prepared from cortex of newborn (P1-P2) Sprague-Dawley rats as previously described [17, 37]. In brief, the rats were decapitated and cortices were carefully dissected. The tissue was mechanically passed through a nylon mesh ( $80 \mu \mathrm{m}$ mesh size) into culture medium. The medium consisted of MEM supplemented to the following composition: $20 \%$ (v/v) FBS, $1 \%$ penicillin-streptomycin, 1.6 times the concentrations of amino acids and 3.2 times the concentration of vitamins (in comparison to MEM), 1.6 mML-glutamine, $7.15 \mathrm{mM}$ glucose and $48.5 \mathrm{mM} \mathrm{NaHCO}$. The cells were cultured in a humidified atmosphere of $95 \%$ air and $5 \% \mathrm{CO}_{2}$. The medium was changed after 3 days in culture and thereafter three times a week. This procedure results in an astrocyte-rich culture with ca $10 \%$ microglia. Cells were used after 7-10 days in culture when a near-confluent monolayer had been formed.

For short-term experiments ( $24 \mathrm{~h}), 1 \mathrm{~h}$ before treatments, culture medium was replaced by fresh DMEM and then exposed to the different treatments for $24 \mathrm{~h}$. After that time, cultures were washed with ice-cold PBS and used for Western Blot determinations. For the $72 \mathrm{~h}$ experiments, cultures were exposed to DMEM plus $1 \%$ FBS with or without different concentrations of TNF $a$ for $48 \mathrm{~h}$ after which media was replaced with serum-free DMEM with or without different doses of TNF $a$ and incubation was continued for $24 \mathrm{~h}$ to complete the $72 \mathrm{~h}$ in vitro. The $48 \mathrm{~h}$ incubation in presence of $1 \%$ FBS was to avoid cell death by prolonged trophic factor deprivation.

\section{Western Blot Analysis}

After treatments, cultures were washed with ice-cold PBS and lysed in Tris-buffered saline pH 7.6 (TBS), $1 \%$ Triton X-100, EDTA 1 mM, EGTA $1 \mathrm{mM}$ plus complete protease inhibitors cocktail (Roche; Stockholm, Sweden). Cell lysates were mixed with 5× Laemmeli sample buffer and boiled for $5 \mathrm{~min}$. Then equal amount of protein $(30 \mu \mathrm{g})$ were resolved on 
$10 \%$ SDS-PAGE in a MOPS or MES buffer (Invitrogen; Carlsbad, USA) and electroblotted at $40 \mathrm{~V}$ for $70 \mathrm{~min}$ at $4{ }^{\circ} \mathrm{C}$ to nitrocellulose (Bio-Rad; Hercules, USA). The membranes were blocked for $1 \mathrm{~h}$ at room temperature $(\mathrm{RT})$ in $5 \%(\mathrm{w} / \mathrm{v})$ dry skimmed milk (Semper Mjölk; Sundyberg, Sweden) in TBS with $0.1 \%$ Tween 20 (TBST). Then, the membranes were incubated overnight at $4{ }^{\circ} \mathrm{C}$ with the corresponding primary antibodies (anti-phospho-p38 and anti-phospho-Ser9-GSK3 $\beta$ were from New England Biolabs (Beverly, USA). TNFa and anti-Nrf2 were from R\&D Diagnostics (Minneapolis, USA). Anti-Keap1, anti- $a$ tubulin, anti- $\gamma$ GCL-C and anti- $\gamma$ GCL-M antibodies were from Santa Cruz Biotechnology (Heidelberg, Germany)) in $5 \%$ bovine serum albumin (BSA)-TBST, extensively washed with TBST solution and incubated with the correspondent secondary antibodies (peroxidaseconjugated anti-rabbit and anti-mouse secondary antibodies were from Vector Laboratories (Burlingame, USA)) for $1 \mathrm{~h}$ at RT. Finally, the blots were rinsed and the peroxidase reaction was developed by enhanced chemiluminescence SuperSignal@ West Dura Extended Duration Substrate (Thermo Scientific; Rockford, USA). Blots were stripped in RestoreTM Plus Western Blot Stripping Buffer (Thermo Scientific; Rockford, USA) and were reprobed sequentially.

Images were captured with a Fujifilm Image Reader LAS-1000 Pro v2.6 (Stockholm, Sweden) and the different band intensities (density arbitrary units) corresponding to immunoblot detection of protein samples were quantified using the Fujifilm Multi Gauge v3.0 software (Stockholm, Sweden).

\section{Cytotoxicity and Viability Assays}

Cell death was quantified by measurement of lactate dehydrogenase (LDH) release into the medium. LDH levels were determined using a commercial kit (Roche; Stockholm, Sweden). The LDH level corresponding to complete cell death was determined in sister cultures exposed to Triton X-100 (1\% final concentration) for $24 \mathrm{~h}$. In the case of $72 \mathrm{~h}$ treatments, after $48 \mathrm{~h}$ of incubation with DMEM with $1 \% \mathrm{FBS}$ with or without different concentrations of TNFa, the media were changed to fresh serum-free DMEM with or without different concentrations of TNF $a$ and incubation was carried out to complete the $72 \mathrm{~h}$ in vitro. An aliquot of media was obtained for measuring LDH levels to establish if different treatments for 24 or $72 \mathrm{~h}$ had any toxic effects on these cultures. Immediately after the 24 or $72 \mathrm{~h}$ treatment with TNFa, media was replaced with fresh serum-free DMEM. Cell cultures were then exposed to $\mathrm{H}_{2} \mathrm{O}_{2} 250 \mu \mathrm{M}$ for $3 \mathrm{~h}$, after which an aliquot of media was taken to measure LDH levels. Background LDH levels were determined in untreated sister cultures and subtracted from experimental values to yield the signal specific for experimentally-induced injury. Percentage of cell death in experimental conditions was calculated using the formula: $[\%$ of cell death $=(($ experimental value $-\mathrm{BK}) /(\mathrm{FK}-\mathrm{BK})) * 100]$, where BK stands for "blank" (sham wash) and FK stands for "full kill" (complete cell death).

\section{Transfections and Reporter Gene Analysis}

The ARE reporter gene vector along with a Renilla luciferase expression vector from the Cignal $^{\mathrm{TM}}$ Antioxidant Response Reporter Kit (SABiosciences; Frederick, USA) were transiently transfected into $10^{5}$ astroglial cells using Lipofectamine ${ }^{\mathrm{TM}}$ Reagent (Invitrogen; Merelbeke, Belgium) according to the manufacture's recommendation. After $18 \mathrm{~h}$ medium was removed and changed with fresh serum-free DMEM and $2 \mathrm{~h}$ later, cells were stimulated as described in each case. Stimulation was allowed to proceed for another $18 \mathrm{~h}$ before cells were harvested, washed with phosphate saline buffer pH 7.4 (PBS) and lysed in cell lysis buffer (Promega; Nacka, Sweden). Luciferase activity (both firefly and Renilla luciferase activity) were evaluated using the Dual-Luciferase ${ }^{\circledR}$ Reporter Assay System (Promega). Values were normalized to the Renilla luciferase activity (Promega). The Dual-Luciferase ${ }^{\circledR}$ Reporter Assay System refers to the simultaneous expression and measurement of two 
individual reporter enzymes within a single system. Thus, the "experimental" reporter (firefly luciferase) is correlated with the effect of specific experimental conditions whereas the activity of the cotransfected "control" (Renilla luciferase) reporter provides an internal control for the efficiency of the transfection. Firefly and Renilla luciferase activity were measured as light emission over a period of $10 \mathrm{~s}$ each time in a VICTOR ${ }^{2}$ Multilabel Counter (Wallac; Turku, Finland).

\section{siRNA Mediated Knock-Down of Nrf2}

Nrf2 expression was down-regulated by using siRNA technique as previously described [26]. Briefly, astrocyte-rich cultures were transiently transfected using ON-TARGET-plus SMARTpool siRNA against rat Nrf2 (Thermo Scientific Dharmacon, Rockford, USA). ONTARGET plus scrambled sequence pool (Thermo Scientific Dharmacon, Rockford, USA) was used as negative control. The transfection into $10^{5}$ astroglial cells was initiated by incubating the cultures with OptiMEM (Invitrogen, Merelbeke, Belgium) for $30 \mathrm{~min}$. Nrf2 ON-TARGETplus SMART-pool siRNA or ON-TARGET plus scrambled sequence (100 $\mathrm{nM}$, final concentration) was mixed with Lipofectamine 2000 (Invitrogen, Merelbeke, Belgium) in Opti-MEM and incubated for $20 \mathrm{~min}$ prior to addition to the astrocyte-rich cultures. After $5 \mathrm{~h}$, OptiMEM containing $20 \%$ FBS was added to the transfection mixture and the astrocyte-rich cultures were incubated for $19 \mathrm{~h}$. The cultures were thereafter further incubated in serum-free DMEM with or without TNFa. The efficiency of the knockdown was evaluated by western blot (Fig. 2c) using anti-Nrf2 antibody. The optical densities of Nrf2 blot was correlated to the densities of tubulin and showed a decrease in the level of Nrf2 by approximately $80 \%$ compared to untreated samples (Fig. 2d).

\section{Statistical Analysis}

Results are presented as mean \pm standard error mean (SEM) of at least three separate experiments with different cell preparations. One way ANOVA followed by the Bonferroni's post hoc test for multiple comparison were used to determine statistical significance $(95 \% ; p<0.05)$.

\section{Results}

\section{Effect of $24 \mathrm{~h}$ TNFa on the Astroglial Nrf2 System}

First we evaluated the effects of $24 \mathrm{~h}$ exposure of astrocyte-rich cultures to TNF $a$ on the components of the inducible Nrf2 system, $\gamma$ GCL activity and GSH content (Fig. 1). As shown in Fig. 1a, b, $10 \mathrm{ng} / \mathrm{mL}$ of TNF $a$ induced an increased expression of Nrf2, ZGCL-C and $\gamma$ GCL-M but reduced the level of Keap1. Next, the effects of different doses of TNF $a$ on the $\gamma$ GCL activity (Fig. 1c) and the GSH content (Fig. 1d) were evaluated. Together these experiments showed that the highest dose of TNF $a$ tested $(10 \mathrm{ng} / \mathrm{mL})$ increased the enzymatic activity of $\gamma \mathrm{GCL}$ and the content of GSH likely via activation of Nrf2.

The phenolic compound $t \mathrm{BHQ}$ has been shown to increase both GSH levels and $\gamma \mathrm{GCL}$ activity in astrocytes $[12,27]$ and its protective effects have been associated with the activation of the Nrf2 system [23,52]. We therefore investigated whether $t$ BHQ could further increase the intracellular levels of GSH and $\gamma \mathrm{GCL}$ activity in astrocyte-rich cultures treated for $24 \mathrm{~h}$ with $10 \mathrm{ng} / \mathrm{mL}$ of TNF $a$. Indeed, and as shown in Fig. 1e, f, co-treatment with TNF $a(10 \mathrm{ng} / \mathrm{mL})$ and $t \mathrm{BHQ}(20 \mu \mathrm{M})$ increased both the $\gamma \mathrm{GCL}$ activity and GSH content in astrocyte-rich cultures in comparison to treatment with either $t \mathrm{BHQ}$ or TNF $a$ alone. 


\section{Oxidative Stress Response of Astrocyte-Rich Cultures Treated for $24 \mathrm{~h}$ with TNFa}

Next we wanted to evaluate if $24 \mathrm{~h}$ exposure to TNF $a$ increased the astroglial resistance to oxidative stress. As show in Fig. 2a, treatment with $10 \mathrm{ng} / \mathrm{mL}$ TNFa for $24 \mathrm{~h}$ resulted in an increased protection against the oxidative stress induced by $250 \mu \mathrm{M} \mathrm{H}_{2} \mathrm{O}_{2}$. This correlates well with the increased levels of GSH and $\gamma \mathrm{GCL}$ activity in cells treated with TNFa (10 ng/ $\mathrm{mL}$ ) for $24 \mathrm{~h}$ (see Fig. 1c, d). Next we investigated if the protective effects of TFNa were due to increased production of GSH. This was performed by the use of a GCL-inhibitor, BSO, that blocks de novo synthesis of GSH. Treatment of the cultures with $1 \mathrm{mM}$ of BSO for $24 \mathrm{~h}$ completely reversed the protective effects of TNFa against the oxidative stress (Fig. $2 b)$. To confirm that the activation of the Nrf2 system was involved in the protective effects of TNFa, we used the siRNA technology to knock-down Nrf2 expression (Fig. 2c) by about $80 \%$ (Fig. 2d). As shown in Fig. 2e TNFa has no protective effect on astrocyte-rich cultures against oxidative stress when Nrf2 is down-regulated by siRNA. Interestingly, co-treatment with $t \mathrm{BHQ}(20 \mu \mathrm{M})$ and $10 \mathrm{ng} / \mathrm{mL}$ TNF $a$ of astrocyte-rich cultures subjected to $\mathrm{H}_{2} \mathrm{O}_{2^{-}}$ induced oxidative stress caused enhanced protection compared to treatment with only $t \mathrm{BHQ}$ or TNFa (Fig. 2f). This indicates that the Nrf2 activation is not saturated by either $20 \mu \mathrm{M}$ $t$ BHQ or $10 \mathrm{ng} / \mathrm{ml}$ TNFa. Supplementary Fig. 1 shows the LDH levels of astroglial-enriched cultures subjected to different treatments for $24 \mathrm{~h}$ or $72 \mathrm{~h}$ before the exposure to $\mathrm{H}_{2} \mathrm{O}_{2}$ $250 \mu \mathrm{M}$.

\section{Signalling Pathways Involved in TNFa Activation of the Nrf2-System}

In order to elucidate the signalling pathways involved in the effects of $10 \mathrm{ng} / \mathrm{mL}$ TNF $a$ on Nrf2 transcriptional activity, we transiently transfected astrocyte-rich cultures with a commercial ARE-LUC reporter gene vector along with a Renilla luciferase expression vector. Transfected cells were treated for $24 \mathrm{~h}$ with TNF $a$ in the presence or absence of various signalling pathway inhibitors (Fig. 3). Treatment with $10 \mathrm{ng} / \mathrm{mL}$ of TNFa for $24 \mathrm{~h}$ activated ARE-medieated transcription, as reflected by the higher luciferase activity compared to control. Inhibition of the ERK1/2 MAPK (Fig. 3a), JNK MAPK (Fig. 3b) and Akt (Fig. 3d) signalling pathways blocked the increment in the transcriptional activity induced by TNF $a$. In contrast, when the transiently transfected astrocyte-rich cultures were treated with TNF $a$ for $24 \mathrm{~h}$ and the p38 MAPK (Fig. 3c) or the GSK3 $\beta$ inhibitor (Fig. 3e) higher luciferase activities were detected. Interestingly, when the two inhibitors (SB203580 and lithium chloride) were added together, the activating effects on ARE-mediated transcription were additive (Fig. 3f). In summary, the results in Fig. 3 show that ERK1/2, JNK and Akt pathways can enhance ARE-mediated transcription whereas activation of p38 and GSK $3 \beta$ has opposite negative effects.

\section{Effect of Prolonged TNFa Treatment on the Astroglial Nrf2 System}

In our earlier studies we showed that medium from LPS activated microglia can have positive effects after $24 \mathrm{~h}$ but negative effects after $72 \mathrm{~h}$ on the Nrf2-system in astrocyte-rich cultures [6]. Similar dual effects of LPS with protection after $24 \mathrm{~h}$ and sensitisation after 72 $\mathrm{h}$ to an hypoxic-ischemic insult was demonstrated in neonatal rats [57]. Since the $24 \mathrm{~h}$ exposure of astrocyte-rich cultures to TNFa induced a similar increase in the antioxidant defence in the astrocyte-rich cultures, we decided to investigate the effects of prolonged (72 h) exposure of astrocyte-rich cultures to TNFa on components of the inducible Nrf2 system. We first analysed the effects of various doses of TNF $a$ on astroglial Nrf2, Keap1, zGCL-C and $\gamma$ GCL-M protein expression (Fig. 4a). In contrast to the effects after $24 \mathrm{~h}$, TNFa treatment for $72 \mathrm{~h}$ decreased the expression of Nrf2, $\gamma$ GCL-C and $\gamma$ GCL-M but increased the level of Keap1 (Fig. 4a). These effects were observed at both 1 and $10 \mathrm{ng} / \mathrm{mL} \mathrm{TNFa}$ concentrations, whereas treatment with $0.5 \mathrm{ng} / \mathrm{mL}$ resulted in decreased levels of $\gamma \mathrm{GCL}-\mathrm{C}$ and $\gamma$ GCL-M. Next, the effects of different doses of TNFa on the $\gamma$ GCL activity (Fig. 4c) and the GSH content (Fig. 4d) were evaluated. In agreement with the decreased protein 
levels of $\gamma$ GCL-C and $\gamma$ GCL-M, TNF $a$ at all concentrations decreased both the enzymatic activity of $\gamma \mathrm{GCL}$ and the content of GSH.

Interestingly, and in contrast to the results from cultures treated for $24 \mathrm{~h}$ with TNF $a$, addition of $t \mathrm{BHQ}(20 \mu \mathrm{M})$ to cultures treated for $48 \mathrm{~h}$ with $10 \mathrm{ng} / \mathrm{mL}$ TNF $a$ did not elevate the activity of $\gamma \mathrm{GCL}$ activity and the GSH content (Fig. 4e). As suspected from the detrimental effects on the Nrf2 system by TNF $a$ treatment for $72 \mathrm{~h}$ the vulnerability to oxidative stress $\left(250 \mu \mathrm{M} \mathrm{H}_{2} \mathrm{O}_{2}\right)$ was enhanced (Fig. 5a). As shown in Fig. $5 \mathrm{~b}$ treatment with $t \mathrm{BHQ}(20 \mu \mathrm{M})$ protected non-treated cells from oxidative stress but this positive effect was lost in cultures treated with TNF $a$ for $72 \mathrm{~h}$ (Fig. 5b). To sum up, prolonged treatment (72 h) of astrocyte-rich cultures with TNF $a$ results in decreased anti-oxidant defense, increased vulnerability to oxidative stress and inability to activate the protective Nrf2-system.

The results from the treatment of the astrocytes for $24 \mathrm{~h}$ with TNF $a$ and inhibitors of ERK1/2, JNK, p38 MAPK, Akt, and GSK3 $\beta$ phosphorylation (Fig. 3) showed that activation of ERK1/2, JNK and Akt have positive effects whereas activation of $\mathrm{p} 38$ and GSK $3 \beta$ have negative effects on the Nrf2 system. This is in agreement with our previous study showing that ERK1/2 and JNK MAPKs pathways are involved in maintaining and/or increasing the levels of Nrf2 on astrocytes exposed to microglial-conditioned medium [7]. However, the activation of ERK1/2 and JNK were lost after $72 \mathrm{~h}$ and the negative p38 MAPK and GSK3 $\beta$ effects on Nrf2 levels become more prevalent.This agrees well with earlier studies on the participation of p38 MAPK and GSK3 $\beta$ in the modulation of Nrf2mediated expression of antioxidant enzymes (Cui et al. 2007; [35, 42, 52]). Thus, we inhibited the $\mathrm{p} 38$ and GSK3 $\beta$ signalling pathways and evaluated the levels of Nrf2 and $\gamma$ GCL-M protein expression after $72 \mathrm{~h}$ treatment with TNF $a$ (Fig. 6). These experiments showed that inhibition of p38 MAPK with SB203580 (20 $\mu$ M) and GSK3 $\beta$ with LiCl (5 $\mathrm{mM}$ ) restored the down-regulated levels of both Nrf2 and $\gamma$ GCL-M (Fig. 6c, d).

\section{Discussion}

Treatment of astrocyte-rich cultures with TNF $a(10 \mathrm{ng} / \mathrm{ml})$ caused upregulation of Nrf2, $\gamma \mathrm{GCL}-\mathrm{M}$ and $\gamma \mathrm{GCL}-\mathrm{C}$ after $24 \mathrm{~h}$ and down-regulation following $72 \mathrm{~h}$ treatment $(1,10 \mathrm{ng} /$ $\mathrm{ml})$. These effects agree well with the finding that TNF $a$ increased GSH content in rat hepatocytes by regulating the expression of $2 \mathrm{GCL}-\mathrm{C}$ [33] and that TNF $a$ at $10 \mathrm{ng} / \mathrm{ml}$ after $24 \mathrm{~h}$ increased HO-1 mRNA in human macrophages [16]. It is important to note that none of the treatments with TNF $a$ exerted toxicity per se. However, when the cells were challenged with oxidative stress $\left(\mathrm{H}_{2} \mathrm{O}_{2}\right)$, increased toxicity was observed in cells treated for $72 \mathrm{~h}$ with $\mathrm{TNF} a$ whereas $24 \mathrm{~h}$ treatment protected against oxidative stress. The protection after $24 \mathrm{~h}$ was related to the increased protein levels of $\gamma \mathrm{GCL}$ as an inhibitor of this enzyme, BSO, blocked the protective effect. The protective effect of TNF $a$ may partly involve the NF- $\kappa$ B and AP- 1 transcription factors. The promoter of $\gamma$ GCL-C contains binding sites for NF- $\kappa \mathrm{B}$ subunits and AP-1 $[33,59]$. The promoter for rat $\gamma$ GCL-M contains an ARE sequence but no AP-1 or NF-kB binding sites [59]. Activation of / GCL-M may still be related to AP-1 mediated transcription since c-Jun, which is dependent on AP-1, is a binding partner that enhances transcription by Nrf2 [59]. However, the requirement and importance of Nrf2 as a mediator of the protective effects of TNF $a$ was confirmed by Nrf2 down-regulating by siRNA technology, which blocked the TNF $a$-mediated protection against $\mathrm{H}_{2} \mathrm{O}_{2}$ after $24 \mathrm{~h}$ treatment. In an earlier study on the effects of TNF $a(20 \mathrm{ng} / \mathrm{mL})$ on astrocyte metabolism, no changes in content and release of GSH was observed after $48 \mathrm{~h} \mathrm{[15].} \mathrm{In} \mathrm{that} \mathrm{study} \mathrm{normal}$ serum containing medium was used which will likely decrease the availability and free concentration of TNF $a$ in comparison to our study where low serum was used. Moreover, in the mentioned study [15], 21 day cultures whereas we used 7-10 day cultures which may be 
important for the response of the cells. For example it has been shown that the Nrf2-system is less responsive in cultures older than 10 days in culture [49].

The receptors activated by TNF $a$ and responsible for the up-and down-regulation of the Nrf2-system were not elucidated in this study. However, TNFR1 could be involved in both these effects of TNF $a$ as time-related sensitization and protection against oxygen-glucose deprivation in organotypic slices by TNF $a$ was elicited via the TNFR1 subtype and not the TNFR2 subtype [30]. Interestingly, TNF $a$ can induce TNFR2 receptors which imply that these receptors could be involved in the dual effects reported here [29]. Another factor that could be of importance is that TNF $a$ can induce synthesis and release of other cytokines such as IL-6 [46]. However, it should be noted that the dual effects by TNF $a$ treatment for 24 or $72 \mathrm{~h}$ in organotypic slices was lost by genetic deletion of TNFR1, indicating that TNF $a$ indeed is the major player when added exogenously [30]. Studies are in progress to determine if TNF $a$ induce synthesis of other proinflammatory cytokines and/or changes in the receptor population of TNFR1 and TNFR2 that could be involved in the reported modulation of the neuroprotective Nrf2-inducible antioxidant system in astrocytes.

The ability of $t \mathrm{BHQ}$ to induce the Nrf2 system, elevate GSH and $2 \mathrm{GCL}$ activity and protect astrocyte-rich cultures against $\mathrm{H}_{2} \mathrm{O}_{2}$ was preserved after $24 \mathrm{~h}$ also in the presence of TNF $a$. Moreover, the effects of TNF $a$ and $t \mathrm{BHQ}$ were in fact additive. The reasons for this additive effect were not investigated further but could be due to higher levels of GSH with both treatments via $\mathrm{Nrf} 2$, i.e. the activation of $\mathrm{Nrf} 2$ is not saturated with TNF $a$ or $t \mathrm{BHQ}$ alone. Alternatively, complementary protective functions are elevated by $t \mathrm{BHQ}$ and TNF $a$, possibly via AP-1 and/or NF- $\kappa$ B as discussed above.

The effects after $24 \mathrm{~h}$ treatment with TNF $a$ on ARE-mediated transcription after $24 \mathrm{~h}$ were evaluated by the use of a commercial plasmid containing multiple ARE-sequences (but no AP-1 or NF- $x$ B binding sites) that was coupled to a sequence coding for luciferase. From the experiments using the ARE-LUC plasmid it was obvious that TNF $a$ mediates a robust increase in ARE-mediated transcription. Using different inhibitors of kinases we found that blockers of JNK, ERK1/2 and Akt completely inhibited the TNF $a$-induced increase in AREmediated transcription after $24 \mathrm{~h}$. In contrast inhibiting GSK3 $\beta$ and p 38 MAPK had positive and additive effects. The finding that ERK1/2 and JNK have positive effects on AREdependent transcription is in agreement with earlier findings [58]. These results are also in agreement with our earlier reports [6,7]. It is not fully clear if Nrf2 itself is phosphorylated, as mutations of phosphorylationsites on Nrf2 make little difference concerning stability of Nrf2 and transactivation potency $[48,53]$. It is possible that some other co-factors are activated or co-repressors are inactivated by these kinases [48, 53]. For example, CREB binding protein (CBP) is a cofactor that, when phosphorylated, binds to Nrf2 and increase transactivation [47]. Although the full biochemical background for the positive effects of $\mathrm{TNF} a$ on the Nrf2 system was not elucidated here, it is clear that TNF $a$ activates AREmediated transcription via Nrf2, although this does not rule out indirect participation of other transcription factors such as AP-1 and NF- $\kappa$ B [59].

Inhibitors of $\mathrm{p} 38$ MAPK and GSK3 $\beta$ together increased ARE-stimulated transcription additively after $24 \mathrm{~h}$ treatment with TNF $a$ indicating that different sites and/or proteins were phosphorylated. The mechanisms are likely due to that both activated GSK3 $\beta$ and p38 MAPK can cause export of Nrf2 from the nucleus leading to enhanced breakdown via the proteasome pathway $[45,63]$.

The decrease in Keap1 protein levels after $24 \mathrm{~h}$ treatment with TNF $a$ could be one reason for the increased levels of Nrf2, as this will result in less Nrf2 directed for ubiquitination and proteasomal degradation [8]. The decreased level of Keap1 is similar to that found in a 
recent in vivo study showing that Keap1 is decreased after MCAO occlusion in the periinfarct region [54]. We reported earlier that inhibition of the proteasome in astrocyte-rich cultures increased the levels of Keap1 in astrocyte-rich cultures treated for $24 \mathrm{~h}$ with medium from microglia activated with $10 \mathrm{ng} / \mathrm{mL}$ of LPS [6]. Thus, Keap1 itself can be targeted for proteasomal degradation and one important factor that determines degradation of Keap1 is dephosphorylation, which increases instability and elevates proteasomal breakdown [20].

Treatment of the astrocyte-rich cultures with TNF $a(1$ and $10 \mathrm{ng} / \mathrm{ml})$ for $72 \mathrm{~h}$ dramatically reduced Nrf2/2GCL-M/2GCL-C levels whereas Keap1 levels were increased. This agrees well with an earlier long-term study on inflamed kidney [24]. In our recent report on the effects on astrocyte-rich cultures treated for $72 \mathrm{~h}$ with medium from LPS-activated microglia we found decreased levels of Nrf2/ $/$ GCL-M but here Keap1 was also downregulated [6]. The factors behind the dynamic changes in Keap1, which may relate to phosphorylation [20], are highly interesting as Keap1 has been shown to regulate the activity of IKKB/NF- $x$ B activity [26] and the degree of Bcl-2 degradation by the proteasome [36].

The decreased levels of $\mathrm{Nrf} 2 / \gamma \mathrm{GCL}$ in astrocyte-rich cultures after $72 \mathrm{~h}$ treatment with TNF $a$ were counteracted by blockers of $\mathrm{p} 38$ MAPK and GSK $3 \beta$. The negative effect of $\mathrm{p} 38$ MAPK on the Nrf2 system is in corroboration with earlier studies in cell lines [63], in murine embryonic fibroblast [35] and we earlier showed that treatment of astrocyte-rich cultures for $72 \mathrm{~h}$ with medium from LPS-activated microglia down-regulated the levels of proteins in the Nrf2 system in a p38 MAPK-sensitive fashion [6]. Inhibition of p38 MAPK activation was protective and restored the inducibility of the Nrf2 system [6]. The reason for the negative effects of activated p38 MAPK may be related to a decreased nuclear localization and increased degradation of Nrf2 [35]. An alternative and intriguing explanation is that p38 MAPK could indirectly decrease the acetylation levels of Nrf2, leading to nuclear export and degradation. Recent studies have shown that $\mathrm{CBP} / \mathrm{p} 300$, which has acetylase transferase activity, elevate Nrf2-acetylation and Nrf2-mediated transcription [22]. Interestingly, activation of p38 MAPK can initiate degradation of p300 [39] and thus decrease the acetylation levels and binding efficacy of Nrf2 to ARE-sequences. In accordance, we showed that the non-selective HDAC inhibitors valproate and trichostatin-A restored Nrf2 and levels of $\gamma$ GCL-M strongly indicating that acetylation levels, that partly appear to depend on p38 MAPK activity, is an important factor in Nrf2 stability [7]. A similar theoretical explanation for the down-regulatory effects of GSK $3 \beta$ is that increased activation of Akt, which decreases activation of GSK $3 \beta$ via phosphorylation, decreases HDAC activity whereas activation of GSK3 $\beta$ has the opposite effect [4]. A putative mechanism in our case is thus that activated GSK $3 \beta$ decreases acetylation of Nrf2, which leads to elevated degradation of Nrf2.

Concerning the long-term negative effects of TNF $a$ on Nrf $2 / \gamma \mathrm{GCL}-\mathrm{M} / \gamma \mathrm{GCL}-\mathrm{C}, \mathrm{NF} \kappa \mathrm{B}$ may also be involved. Thus, it has been shown that the p65 subunit of NF $\kappa$ B can decrease Nrf2 mediated-transcription via elevated levels of nuclear Keap1 with dissociates Nrf2 from ARE-sequences [62]. This may be partly due to the deprivation of CBP (CREB-binding protein), which facilitates recruitment of HDAC3 to small Maf-proteins [28]. The effect being deacetylation of local histones and Nrf2, followed by decreased ARE-mediated transcription.

The strong effects of kinase activity on ARE-activated transcription after treatment with TNF $a$ thus indicate that the "background" kinase activation in combination with effects of $\mathrm{TNF} a$ on these kinases can be deterministic for transactivation by Nrf2. The kinase activity may thus be one key to understanding the various effects of TNFa, neuroinflammation and its opposite effects in normal and diseased brain as it has been discussed earlier [38]. 
When hypoxia-ischemia in 8-day rats was induced $24 \mathrm{~h}$ after LPS injection a preconditioning protective effect on brain damage was demonstrated, whereas sensitization occurred $72 \mathrm{~h}$ following the LPS-injection [57]. This correlates well with our in vitro studies showing time-dependent up- and down-regulation of the Nrf2-system in astrocyte-rich cultures by inflammatory mediators from microglia [6]. It is interesting to note that earlier studies have shown decreased Akt and GSK3 $\beta$ phosphorylation after hypoxia-ischemia induced brain damage in rats $[3,60]$. The activation of GSK3 $\beta$ by both inflammation and hypoxia-ischemia may, in addition to cause export of Nrf2 from the nucleus [42], have longlasting effects via activation of HDACs and DNA methyltransferases that may be important factors for the long-term outcome after an insult [7, 40].

In conclusion, treatment of astrocyte-rich cultures with TNF $a$ for $24 \mathrm{~h}$ increased $\mathrm{Nrf} 2$ mediated transcription and protected against oxidative stress in an Nrf2-dependent way. In contrast treatment for $72 \mathrm{~h}$ decreased the Nrf2-system and made the cells more vulnerable to oxidative stress. The elevated Nrf2-mediated transcription was dependent on activation of ERK1/2, JNK and Akt, whereas down-regulation could be restored by inhibitors of GSK3 $\beta$ and $\mathrm{p} 38$ MAPK signaling pathways. The implications include that TNF $a$ can protect astrocytes only if the Nrf2-system is functioning. In disease states where the Nrf2 system is dysfunctional, i.e. for example in Alzheimer's disease the protective effect of TNF $a$ is lost [41].

\section{Supplementary Material}

Refer to Web version on PubMed Central for supplementary material.

\section{Acknowledgments}

The expert technical assistance of Barbro Jilderos, Anne-Marie Alborn and Birgit Linder is gratefully acknowledged. The work was supported by the Swedish Research Council/Medicine, Parkinson-fonden and A hlénstiftelsen. MS is supported by the National Institutes of Health (GM 44842). CM is supported by Neurobid (241778).

\section{Abbreviations}

$\begin{array}{ll}\text { ARE } & \text { Antioxidant responsive element } \\ \text { BSO } & \text { Buthionine sulfoxide } \\ \text { DMEM } & \text { Dulbecco's Modified Eagle's Medium } \\ \text { FBS } & \text { Foetal bovine serum } \\ \text { rGCL } & \text { Gamma-glutamylcysteine ligase } \\ \text { rGCL-C } & \text { Gamma-glutamylcysteine ligase catalytic subunit } \\ \text { rGCL-M } & \text { Gamma-glutamylcysteine ligase modulatory subunit } \\ \text { GSH } & \text { Glutathione } \\ \text { GSK3 } \beta & \text { Glycogen synthase kinase-3 beta } \\ \text { Keap1 } & \text { Kelch-like ECH-associated protein 1 } \\ \text { ERK1/2 } & \text { Extracellular regulated kinase } \\ \text { FBS } & \text { Foetal bovine serum } \\ \text { JNK } & \text { c-Jun N-terminal kinase }\end{array}$




$\begin{array}{ll}\text { LPS } & \text { Lipopolysaccaride } \\ \text { MAPKs } & \text { Mitogen-activated protein kinases } \\ \text { MCM } & \text { Microglia-conditioned medium } \\ \text { MEK } & \text { Mitogen-activated protein kinase kinase } \\ \text { MEM } & \text { Modified Eagle's Medium } \\ \text { MnSOD } & \text { Manganese superoxide dismutase } \\ \text { NDA } & \text { Naphthalene-2,3-dicarboxaldehyde } \\ \text { NF- } \boldsymbol{x} \text { B } & \text { Nuclear factor kappa-light-chain-enhancer of activated B cells } \\ \text { Nrf2 } & \text { Nuclear factor-erythroid 2-related factor 2 } \\ \text { PBS } & \text { Phosphate buffered saline } \\ \text { 5-SSA } & \text { 5-Sulfosalicylic acid } \\ \boldsymbol{t B H Q} & \text { Tert-butylhydroquinone } \\ \text { TNF } \boldsymbol{a} & \text { Tumor necrosis factor-alpha }\end{array}$

\section{References}

1. Allaman I, Belanger M, Magistretti PJ. Astrocyte-neuron metabolic relationships: for better and for worse. Trends Neurosci. 2011; 34:76-87. [PubMed: 21236501]

2. Bruce-Keller AJ, Geddes JW, Knapp PE, McFall RW, Keller JN, Holtsberg FW, Parthasarathy S, Steiner SM, Mattson MP. Anti-death properties of TNF against metabolic poisoning: mitochondrial stabilization by MnSOD. J Neuroimmunol. 1999; 93:53-71. [PubMed: 10378869]

3. Brywe KG, Mallard C, Gustavsson M, Hedtjarn M, Leverin AL, Wang X, Blomgren K, Isgaard J, Hagberg H. IGF-I neuroprotection in the immature brain after hypoxia-ischemia, involvement of Akt and GSK3beta? Eur J Neurosci. 2005; 21:1489-1502. [PubMed: 15845077]

4. Chen S, Owens GC, Makarenkova H, Edelman DB. HDAC6 regulates mitochondrial transport in hippocampal neurons. PLoS ONE. 2010; 5(5):e10848. [PubMed: 20520769]

5. Cheng B, Christakos S, Mattson MP. Tumor necrosis factors protect neurons against metabolicexcitotoxic insults and promote maintenance of calcium homeostasis. Neuron. 1994; 12(1):139153. [PubMed: 7507336]

6. Correa F, Ljunggren E, Mallard C, Nilsson M, Weber SG, Sandberg M. The Nrf2-inducible antioxidant defense in astrocytes can be both up- and down-regulated by activated microglia: involvement of p38 MAPK. Glia. 2011; 59:785-799. [PubMed: 21351160]

7. Correa F, Mallard C, Nilsson M, Sandberg M. Activated microglia decrease histone acetylation and Nrf2-inducible anti-oxidant defence in astrocytes: restoring effects of inhibitors of HDACs, p38 MAPK and GSK3beta. Neurobiol Dis. 2011; 44:142-151. [PubMed: 21757005]

8. Cui J, Shao L, Young LT, Wang JF. Role of Glutathione in neuroprotective effects of mood stabilizing drugs lithium and valproate. Neuroscience. 2007; 144:1447-1453. [PubMed: 17184924]

9. Cullinan SB, Gordan JD, Jin J, Harper JW, Diehl JA. The Keap1-BTB protein is an adaptor that bridges Nrf2 to a Cul3-based E3 ligase: oxidative stress sensing by a Cul3-Keap1 ligase. Mol Cell Biol. 2004; 24:8477-8486. [PubMed: 15367669]

10. De Lella Ezcurra AL, Chertoff M, Ferrari C, Graciarena M, Pitossi F. Chronic expression of low levels of tumor necrosis factor-alpha in the substantia nigra elicits progressive neurodegeneration, delayed motor symptoms and microglia/macrophage activation. Neurobiol Dis. 2010; 37:630-640. [PubMed: 19969084]

11. Dringen R, Pfeiffer B, Hamprecht B. Synthesis of the antioxidant glutathione in neurons: supply by astrocytes of Cys-Gly as precursor for neuronal glutathione. J Neurosci. 1999; 19:562-569.

[PubMed: 9880576] 
12. Eftekharpour E, Holmgren A, Juurlink BH. Thioredoxin reductase and glutathione synthesis is upregulated by t-butylhydroquinone in cortical astrocytes but not in cortical neurons. Glia. 2000; 31:241-248. [PubMed: 10941150]

13. Figiel I. Pro-inflammatory cytokine TNF-alpha as a neuroprotective agent in the brain. Acta Neurobiol Exp (Wars). 2008; 68:526-534. [PubMed: 19112477]

14. Fiore M, Angelucci F, Alleva E, Branchi I, Probert L, Aloe L. Learning performances, brain NGF distribution and NPY levels in transgenic mice expressing TNF-alpha. Behav Brain Res. 2000; 112:165-175. [PubMed: 10862948]

15. Gavillet M, Allaman I, Magistretti PJ. Modulation of astrocytic metabolic phenotype by proinflammatory cytokines. Glia. 2008; 56(9):975-989. [PubMed: 18383346]

16. Goven D, Boutten A, Lecon-Malas V, Boczkowski J, Bonay M. Prolonged cigarette smoke exposure decreases heme oxygenase-1 and alters Nrf2 and Bach1 expression in human macrophages: roles of the MAP kinases ERK(1/2) and JNK. FEBS Lett. 2009; 583:3508-3518. [PubMed: 19822148]

17. Hansson E. Cellular composition of a cerebral hemisphere primary culture. Neurochem Res. 1984; 9:153-172. [PubMed: 6204217]

18. Hubbs AF, Benkovic SA, Miller DB, O'Callaghan JP, Battelli L, Schwegler-Berry D, Ma Q. Vacuolar leukoencephalopathy with widespread astrogliosis in mice lacking transcription factor Nrf2. Am J Pathol. 2007; 170:2068-2076. [PubMed: 17525273]

19. Innamorato NG, Rojo AI, Garcia-Yague AJ, Yamamoto M, de Ceballos ML, Cuadrado A. The transcription factor Nrf2 is a therapeutic target against brain inflammation. J Immunol. 2008; 181:680-689. [PubMed: 18566435]

20. Jain A, Lamark T, Sjottem E, Larsen KB, Awuh JA, Overvatn A, McMahon M, Hayes JD, Johansen T. p62/SQSTM1 is a target gene for transcription factor NRF2 and creates a positive feedback loop by inducing antioxidant response element-driven gene transcription. J Biol Chem. 2010; 285:22576-22591. [PubMed: 20452972]

21. Jia JP, Meng R, Sun YX, Sun WJ, Ji XM, Jia LF. Cerebrospinal fluid tau, Abeta1-42 and inflammatory cytokines in patients with Alzheimer's disease and vascular dementia. Neurosci Lett. 2005; 383:12-16. [PubMed: 15936505]

22. Kawai Y, Garduno L, Theodore M, Yang J, Arinze IJ. Acetylation-deacetylation of the transcription factor Nrf2 (nuclear factor erythroid 2-related factor 2) regulates its transcriptional activity and nucleocytoplasmic localization. J Biol Chem. 2011; 286:7629-7640. [PubMed: 21196497]

23. Kensler TW, Wakabayashi N, Biswal S. Cell survival responses to environmental stresses via the Keap1-Nrf2-ARE pathway. Annu Rev Pharmacol Toxicol. 2007; 47:89-116. [PubMed: 16968214]

24. Kim HJ, Vaziri ND. Contribution of impaired Nrf2-Keap1 pathway to oxidative stress and inflammation in chronic renal failure. Am J Physiol Renal Physiol. 2010; 298:F662-F671. [PubMed: 20007347]

25. Kim JE, You DJ, Lee C, Ahn C, Seong JY, Hwang JI. Suppression of NF-kappaB signaling by KEAP1 regulation of IKKbeta activity through autophagic degradation and inhibition of phosphorylation. Cell Signal. 2010; 22:1645-1654. [PubMed: 20600852]

26. Kozlova EN, Takenaga K. A procedure for culturing astrocytes from white matter and the application of the siRNA technique for silencing the expression of their specific marker, S100A4. Brain Res Brain Res Protoc. 2005; 15(2):59-65. [PubMed: 15975528]

27. Lavoie S, Chen Y, Dalton TP, Gysin R, Cuenod M, Steullet P, Do KQ. Curcumin, quercetin, and tBHQ modulate glutathione levels in astrocytes and neurons: importance of the glutamate cysteine ligase modifier subunit. J Neurochem. 2009; 108:1410-1422. [PubMed: 19183254]

28. Liu GH, Qu J, Shen X. NF-kappaB/p65 antagonizes Nrf2-ARE pathway by depriving CBP from Nrf2 and facilitating recruitment of HDAC3 to MafK. Biochim Biophys Acta. 2008; 1783:713727. [PubMed: 18241676]

29. Lung HL, Leung KN, Stadlin A, Ma CM, Tsang D. Induction of tumor necrosis factor receptor type 2 gene expression by tumor necrosis factor- $a$ in rat primary astrocytes. Life Sci. 2001; 68:2081-2091. [PubMed: 11324713] 
30. Markus T, Cronberg T, Cilio C, Pronk C, Wieloch T, Ley D. Tumor necrosis factor receptor-1 is essential for LPS-induced sensitization and tolerance to oxygen-glucose deprivation in murine neonatal organotypic hippocampal slices. J Cereb Blood Flow Metab. 2009; 29:73-86. [PubMed: 18728678]

31. McCoy MK, Tansey MG. TNF signaling inhibition in the CNS: implications for normal brain function and neurodegenerative disease. J Neuroinflamm. 2008; 5:45.

32. Mehindate K, Sahlas DJ, Frankel D, Mawal Y, Liberman A, Corcos J, Dion S, Schipper HM. Proinflammatory cytokines promote glial heme oxygenase-1 expression and mitochondrial iron deposition: implications for multiple sclerosis. J Neurochem. 2001; 77:1386-1395. [PubMed: 11389189]

33. Morales A, García-Ruiz C, Mirandai M, Marí M, Colelli A, Ardite E, Fernández-Checa JC. Tumor necrosis factor increases hepatocellular glutathione by transcriptional regulation of the heavy subunit chain of $\gamma$-glutamylcysteine synthetase. J Biol Chem. 1997; 272(48):30371-30379. [PubMed: 9374527]

34. Morgan MJ, Liu ZG. Reactive oxygen species in TNFalpha-induced signaling and cell death. Mol Cells. 2010; 30:1-12. [PubMed: 20652490]

35. Naidu S, Vijayan V, Santoso S, Kietzmann T, Immenschuh S. Inhibition and genetic deficiency of p38 MAPK up-regulates heme oxygenase-1 gene expression via Nrf2. J Immunol. 2009; 182:7048-7057. [PubMed: 19454702]

36. Niture SK, Jaiswal AK. INrf2 (Keap1) targets Bcl-2 degradation and controls cellular apoptosis. Cell Death Differ. 2011; 18:439-451. [PubMed: 20865015]

37. Nodin C, Nilsson M, Blomstrand F. Gap junction blockage limits intercellular spreading of astrocytic apoptosis induced by metabolic depression. J Neurochem. 2005; 94:1111-1123. [PubMed: 16092948]

38. Perry SW, Dewhurst S, Bellizzi MJ, Gelbard HA. Tumor necrosis factor-alpha in normal and diseased brain: conflicting effects via intraneuronal receptor crosstalk? J Neurovirol. 2002; 8:611624. [PubMed: 12476354]

39. Poizat C, Puri PL, Bai Y, Kedes L. Phosphorylation-dependent degradation of p300 by doxorubicin-activated p38 mitogen-activated protein kinase in cardiac cells. Mol Cell Biol. 2005; 25:2673-2687. [PubMed: 15767673]

40. Popkie AP, Zeidner LC, Albrecht AM, D'Ippolito A, Eckardt S, Newsom DE, Groden J, Doble BW, Aronow B, McLaughlin KJ, White P, Phiel CJ. Phosphatidylinositol 3-kinase (PI3 K) signaling via glycogen synthase kinase-3 (Gsk-3) regulates DNA methylation of imprinted loci. J Biol Chem. 2010; 285:41337-41347. [PubMed: 21047779]

41. Ramsey CP, Glass CA, Montgomery MB, Lindl KA, Ritson GP, Chia LA, Hamilton RL, Chu CT, Jordan-Sciutto KL. Expression of Nrf2 in neurodegenerative diseases. J Neuropathol Exp Neurol. 2007; 66:75-85. [PubMed: 17204939]

42. Rojo AI, Sagarra MR, Cuadrado A. GSK-3beta down-regulates the transcription factor Nrf2 after oxidant damage: relevance to exposure of neuronal cells to oxidative stress. J Neurochem. 2008; 105:192-202. [PubMed: 18005231]

43. Ruedig C, Dringen R. TNF $a$ increases activity of $\gamma$-glutamyl transpeptidase in cultured rat astroglial cells. J Neurosci Res. 2004; 75:536-543. [PubMed: 14743437]

44. Saha RN, Liu X, Pahan K. Up-regulation of BDNF in astrocytes by TNF- $a$ : a case for the neuroprotective role of cytokine. J Neuroimmune Pharmacol. 2006; 1(3):212-222. [PubMed: 18040799]

45. Salazar M, Rojo AI, Velasco D, de Sagarra RM, Cuadrado A. Glycogen synthase kinase-3beta inhibits the xenobiotic and antioxidant cell response by direct phosphorylation and nuclear exclusion of the transcription factor Nrf2. J Biol Chem. 2006; 281:14841-14851. [PubMed: 16551619]

46. Sawada M, Suzumura A, Marunouchi T. TNF alpha induces IL-6 production by astrocytes but not by microglia. Brain Res. 1992; 583(1-2):296-299. [PubMed: 1504836]

47. Shen G, Hebbar V, Nair S, Xu C, Li W, Lin W, Keum YS, Han J, Gallo MA, Kong AN. Regulation of Nrf2 transactivation domain activity. The differential effects of mitogen-activated 
protein kinase cascades and synergistic stimulatory effect of Raf and CREB-binding protein. J Biol Chem. 2004; 279:23052-23060. [PubMed: 15020583]

48. Shen G, Kong AN. Nrf2 plays an important role in coordinated regulation of Phase II drug metabolism enzymes and Phase III drug transporters. Biopharm Drug Dispos. 2009; 30:345-355. [PubMed: 19725016]

49. Shih AY, Johnson DA, Wong G, Kraft AD, Jiang L, Erb H, Johnson JA, Murphy TH. Coordinate regulation of Glutathione biosynthesis and release by Nrf2-expressing glia potently protects neurons from oxidative stress. J Neurosci. 2003; 23(8):3394-3406. [PubMed: 12716947]

50. Shih AY, Li P, Murphy TH. A small-molecule-inducible Nrf2-mediated antioxidant response provides effective prophylaxis against cerebral ischemia in vivo. J Neurosci. 2005; 25:1032110335. [PubMed: 16267240]

51. Singh I, Pahan K, Khan M, Singh AK. Cytokine-mediated induction of ceramide production is redox-sensitive. Implications to proinflammatory cytokine-mediated apoptosis in demyelinating diseases. J Biol Chem. 1998; 273(32):20354-20362. [PubMed: 9685387]

52. Song IS, Tatebe S, Dai W, Kuo MT. Delayed mechanism for induction of gammaglutamylcysteine synthetase heavy subunit mRNA stability by oxidative stress involving p38 mitogenactivated protein kinase signaling. J Biol Chem. 2005; 280:28230-28240. [PubMed: 15946948]

53. Sun X, Erb H, Murphy TH. Coordinate regulation of glutathione metabolism in astrocytes by Nrf2. Biochem Biophys Res Commun. 2005; 326:371-377. [PubMed: 15582588]

54. Tanaka N, Ikeda Y, Ohta Y, Deguchi K, Tian F, Shang J, Matsuura T, Abe K. Expression of Keap1-Nrf2 system and antioxidative proteins in mouse brain after transient middle cerebral artery occlusion. Brain Res. 2011; 1370:246-253. [PubMed: 21075092]

55. Tarkowski E, Liljeroth AM, Minthon L, Tarkowski A, Wallin A, Blennow K. Cerebral pattern of pro- and anti-inflammatory cytokines in dementias. Brain Res Bull. 2003; 61:255-260. [PubMed: 12909295]

56. Vargas MR, Johnson DA, Sirkis DW, Messing A, Johnson JA. Nrf2 activation in astrocytes protects against neurodegeneration in mouse models of familial amyotrophic lateral sclerosis. $\mathrm{J}$ Neurosci. 2008; 28:13574-13581. [PubMed: 19074031]

57. Wang X, Svedin P, Nie C, Lapatto R, Zhu C, Gustavsson M, Sandberg M, Karlsson JO, Romero R, Hagberg H, Mallard C. N-acetylcysteine reduces lipopolysaccharide-sensitized hypoxic-ischemic brain injury. Ann Neurol. 2007; 61:263-271. [PubMed: 17253623]

58. Xu C, Yuan X, Pan Z, Shen G, Kim JH, Yu S, Khor TO, Li W, Ma J, Kong AN. Mechanism of action of isothiocyanates: the induction of ARE-regulated genes is associated with activation of ERK and JNK and the phosphorylation and nuclear translocation of Nrf2. Mol Cancer Ther. 2006; 5:1918-1926. [PubMed: 16928811]

59. Yang H, Magilnick N, Ou X, Lu SC. Tumour necrosis factor alpha induces co-ordinated activation of rat GSH synthetic enzymes via nuclear factor kappaB and activator protein-1. Biochem J. 2005; 391:399-408. [PubMed: 16011481]

60. Yin W, Signore AP, Iwai M, Cao G, Gao Y, Johnnides MJ, Hickey RW, Chen J. Preconditioning suppresses inflammation in neonatal hypoxic ischemia via Akt activation. Stroke. 2007; 38:10171024. [PubMed: 17272774]

61. Yoon K, Jung EJ, Lee SY. TRAF6-mediated regulation of the PI3 kinase (PI3 K)-Akt-GSK3beta cascade is required for TNF-induced cell survival. Biochem Biophys Res Commun. 2008; 371:118-121. [PubMed: 18407828]

62. Yu M, Li H, Liu Q, Liu F, Tang L, Li C, Yuan Y, Zhan Y, Xu W, Li W, Chen H, Ge C, Wang J, Yang X. Nuclear factor p65 interacts with Keap1 to repress the Nrf2-ARE pathway. Cell Signal. 2011; 23:883-892. [PubMed: 21262351]

63. Yu R, Chen C, Mo YY, Hebbar V, Owuor ED, Tan TH, Kong AN. Activation of mitogenactivated protein kinase pathways induces antioxidant response element-mediated gene expression via a Nrf2-dependent mechanism. J Biol Chem. 2000; 275:39907-39913. [PubMed: 10986282]

64. Zhao Z, Chen Y, Wang J, Sternberg P, Freeman ML, Grossniklaus HE, Cai J. Age-related retinopathy in NRF2-deficient mice. PLoS ONE. 2011; 6:e19456. [PubMed: 21559389] 

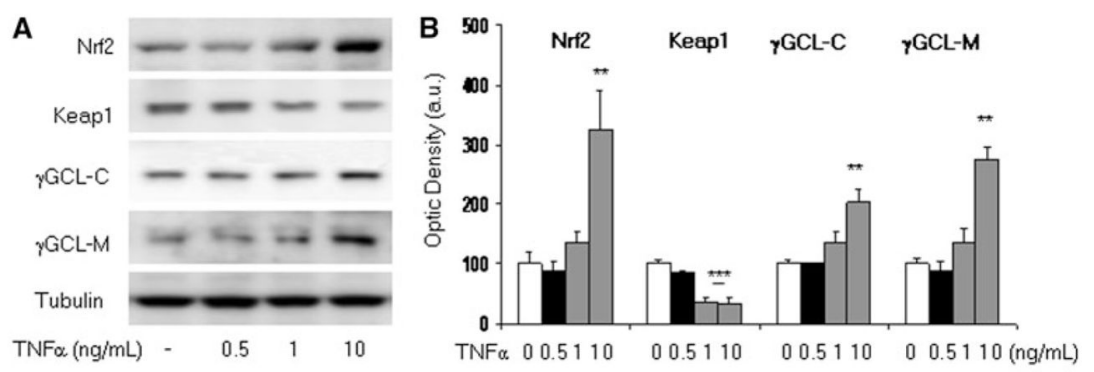

C
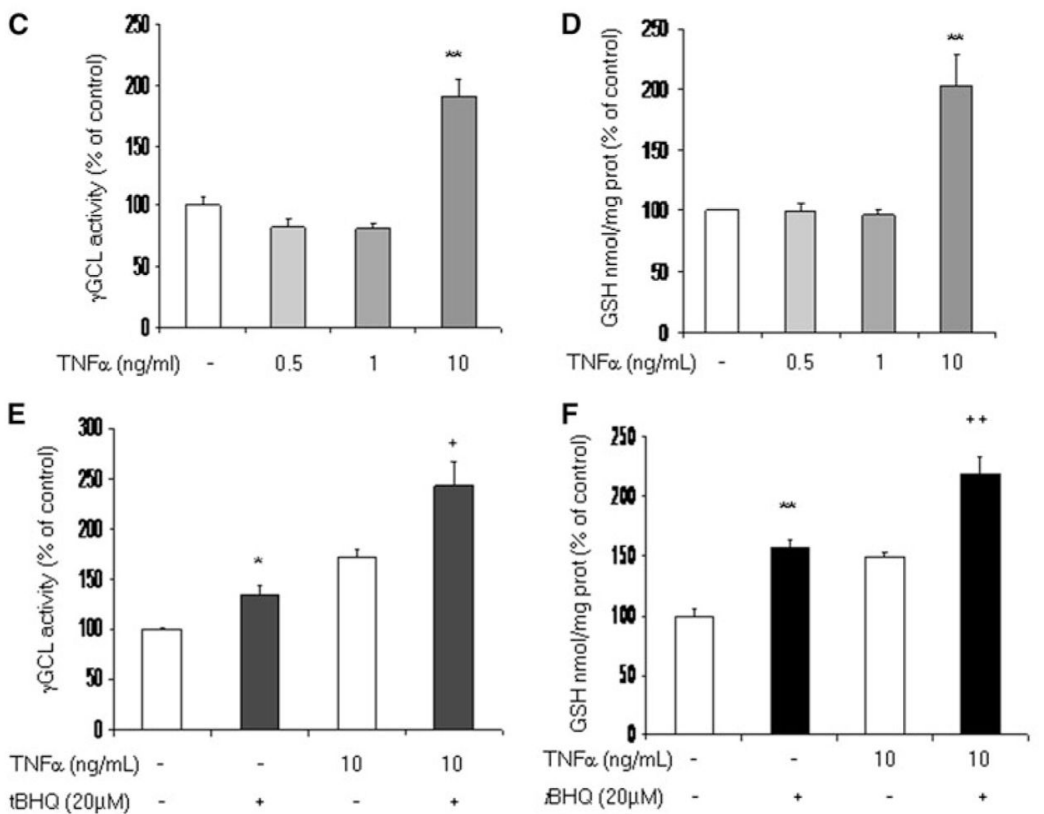

Fig. 1.

$\mathrm{TNF} a$ (24 h treatment) increased astroglial antioxidant defense system. Astrocyte-rich cultures were exposed to different concentrations of TNF $a(0.5,1$ and $10 \mathrm{ng} / \mathrm{mL})$ for $24 \mathrm{~h}$ followed by the protein expression analysis of Nrf2, Keap1, zGCL-C and 2 GCL-M subunits (a). For the western blot, a representative experiment of four independent experiments is shown. In (b), the densitometric analysis is shown. Statistics: $* * p<0.01$ versus control; *** $p<0.005$ versus control. TNF $a(10 \mathrm{ng} / \mathrm{mL})$ induced an increase in $\gamma \mathrm{GCL}$ activity (c) and GSH (d). Results are shown as mean \pm SEM and expressed as percentage of control. Statistics: $* * p<0.01$ versus control. Astrocyte-rich cultures were treated with TNF $a$ in the presence or absence of $20 \mu \mathrm{M} t \mathrm{BHQ}$ and the activity of $\gamma \mathrm{GCL}(\mathbf{e})$ and GSH levels (f) were determined. In both cases, results shown are the mean \pm SEM and expressed as percentage of control. Statistics: $* p<0.05$ versus control; $* * p<0.01$ versus control; $+p<0.05$ versus TNF $a 10 \mathrm{ng} / \mathrm{mL} ;++p<0.01$ versus TNF $a 10 \mathrm{ng} / \mathrm{mL} .(\mathrm{n}=4-6)$ 
A

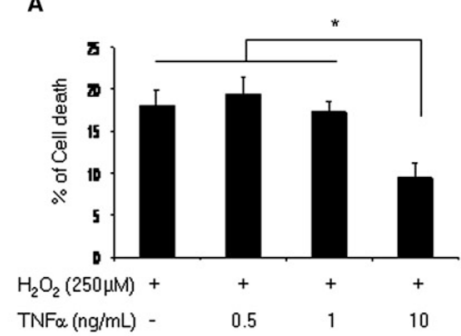

c

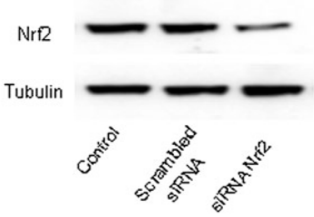

E

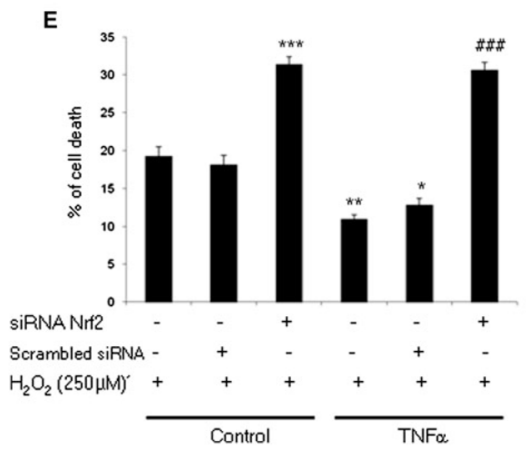

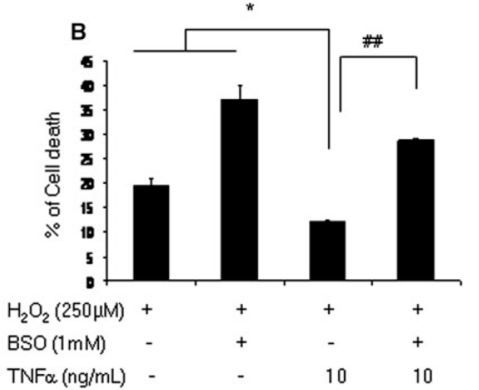

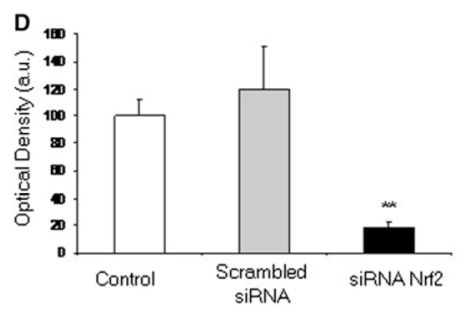

F

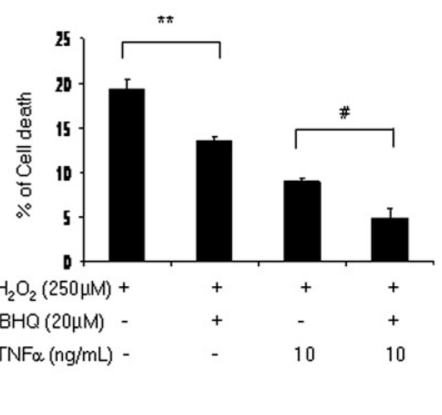

Fig. 2.

TNF $a$ ( $24 \mathrm{~h}$ treatment) protected from cell death induced by $3 \mathrm{~h}$ exposure to $250 \mu \mathrm{M}$ hydrogen peroxide. Astrocyte-rich cultures pre-treated for $24 \mathrm{~h}$ with $10 \mathrm{ng} / \mathrm{mL} \mathrm{TNFa}$ showed higher resistance to oxidative stress (a). Inhibition of $\gamma \mathrm{GCL}$ activity with $1 \mathrm{mM}$ BSO reversed the protective effects of $10 \mathrm{ng} / \mathrm{mL}$ of TNF $a(\mathbf{b})$. Treatment with siRNA directed against Nrf2 lowered the expression of the Nrf-2 protein by approximately $80 \%$ (c). Densitometric analysis of Nrf2 protein expression in astrocyte-rich cultures treated with siRNA directed against Nrf-2. Data are plotted as ratio of the Nrf2/tubulin obtained in each condition (d). Treatment with siRNA against Nrf2 reversed the protective effects of $10 \mathrm{ng} /$ $\mathrm{mL}$ of TNF $a(24 \mathrm{~h})$ against $250 \mu \mathrm{M}$ hydrogen peroxide (e). Co-treatment with the Nrf2inducer $t$ BHQ $20 \mu \mathrm{M}$ potentiated the protective effect of $10 \mathrm{ng} / \mathrm{mL}$ TNF $a$ (f). In all cases, results are shown as the mean \pm SEM. Statistics: $* p<0.05$ versus control; $* * p<0.01$ versus control; *** $p<0.005$ versus control; \#p $<0.05$ versus $\mathrm{TNF} a 10 \mathrm{ng} / \mathrm{mL}$; \#\# $p<0.01$ versus $\mathrm{TNF} a 10 \mathrm{ng} / \mathrm{mL}$; \#\#\#p<0.005 versus TNFa $10 \mathrm{ng} / \mathrm{mL}(\mathrm{n}=4-8)$ 

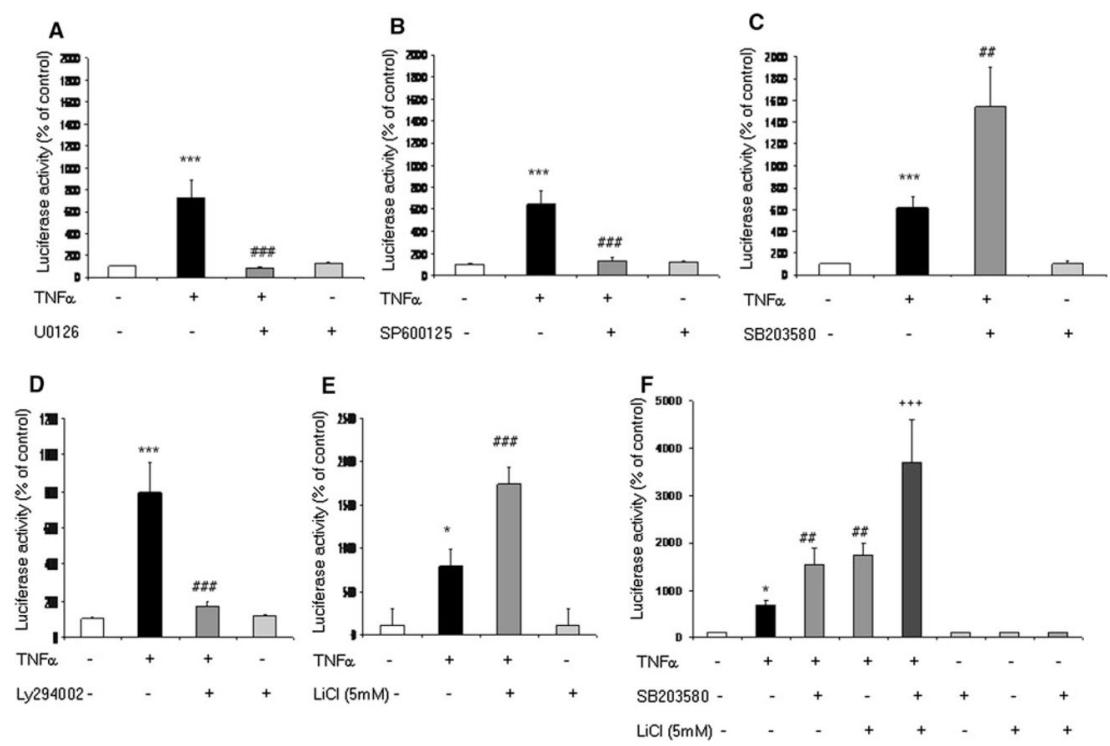

Fig. 3.

Effect of the inhibition of ERK1/2, JNK, p38 MAPK, Akt and GSK3 $\beta$ signalling pathways on the ARE-driven luciferase activity induced by $10 \mathrm{ng} / \mathrm{mL} \mathrm{TNF} a$. Astrocyte-rich cultures were transfected with ARE-Luc reporter gene construct and treated for $24 \mathrm{~h}$ with $10 \mathrm{ng} / \mathrm{mL}$ TNF $a$ in the presence or absence of $10 \mu \mathrm{M} \mathrm{U0126} \mathrm{(a),} 10 \mu \mathrm{M}$ SP600125 (b), $20 \mu \mathrm{M}$ SB203580 (c), $10 \mu \mathrm{M} \mathrm{Ly} 294002$ (d), $5 \mathrm{mM} \mathrm{LiCl}(\mathbf{e})$ and a combination of $5 \mathrm{mM} \mathrm{LiCl}$ and $20 \mu$ M SB203580 (f). Mean \pm SEM of the luciferase activity of astroglial cells transiently transfected with the reporter plasmid ARE-Luc. Data are plotted as percentage of the experimental relative light units/basal relative light units ratio obtained in untreated conditions. Statistics: ${ }^{*} p<0.05$ versus control; $* p<0.05$ versus control; $* * * p<0.005$ versus control; \#\# $p<0.01$ versus TNF $a$; \#\#\# $p<0.005$ versus TNF $a$; $+++p<0.005$ versus $\mathrm{TNF} a+\mathrm{SB} 203580$ or $\mathrm{TNF} a+\mathrm{LiCl}(\mathrm{n}=9)$ 
A

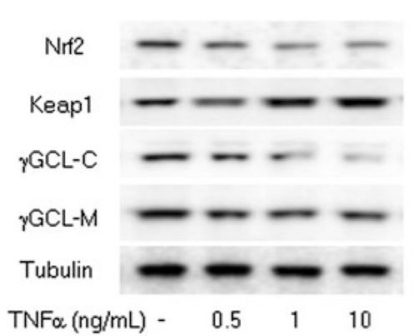

$72 \mathrm{~h}$ B

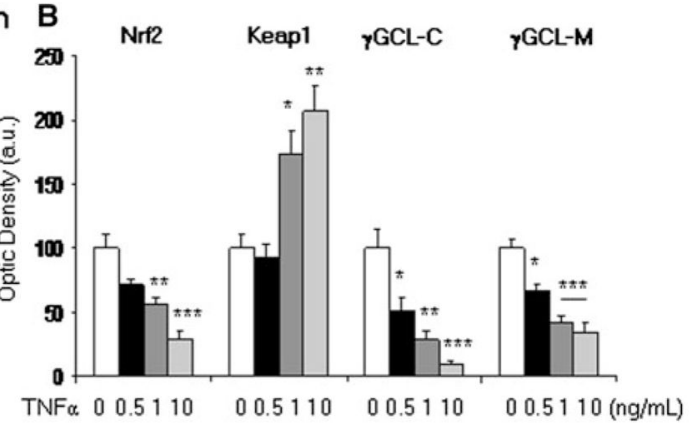

C

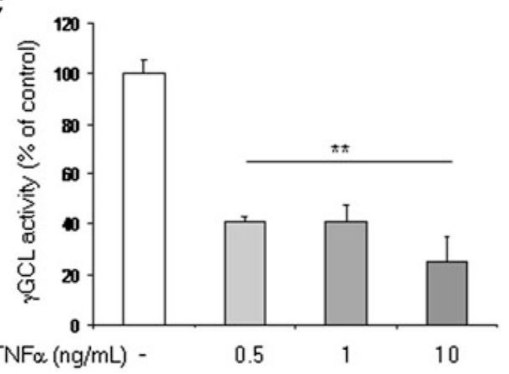

E

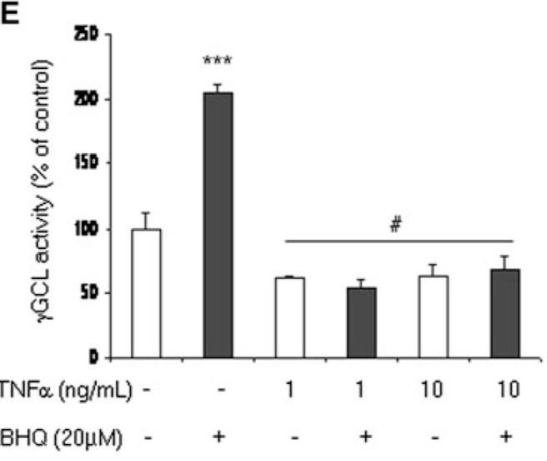

D

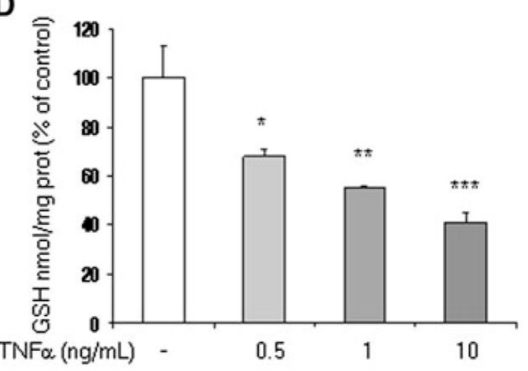

$\mathbf{F}$

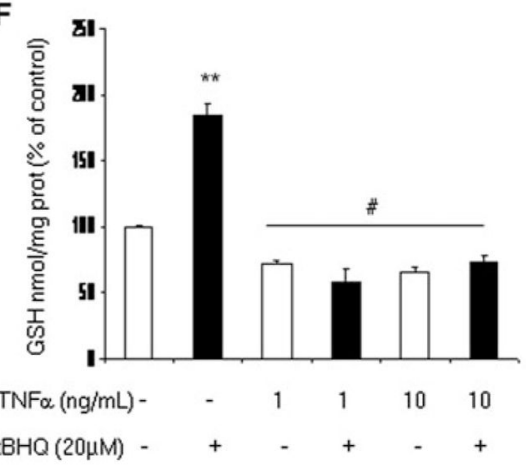

Fig. 4.

$\mathrm{TNF} a$ (72 $\mathrm{h}$ treatment) decreased the astroglial antioxidant defense system. Astrocyte-rich cultures were exposed to different concentrations of TNF $a(0.5,1$ and $10 \mathrm{ng} / \mathrm{mL})$ for $72 \mathrm{~h}$ followed by protein expression analysis of Nrf2, Keap1, / GCL-C and / GCL-M subunits (a). For the western blot, a representative experiment of four independent experiments is shown. In (b), the densitometric analysis is shown. Statistics: ${ }^{*} p<0.05$ versus control; ${ }^{* *} p$ $<0.01$ versus control; *** $p<0.005$ versus control. TNF $a(10 \mathrm{ng} / \mathrm{mL})$ induced a reduction in $\gamma \mathrm{GCL}$ activity (c) as well as on the levels of GSH (d). Results are shown as mean \pm SEM and expressed as percentage of control. Statistics: $* p<0.05$ versus control; $* * p<0.01$ versus control; $* * * p<0.005$ versus control. Astrocyte-rich cultures were treated with TNF $a$ $(10 \mathrm{ng} / \mathrm{mL})$ for $72 \mathrm{~h}$ in the presence or absence of $20 \mu \mathrm{M} t \mathrm{BHQ}$ and the activity of $\gamma \mathrm{GCL}$ (e) and GSH levels (f) were determined. In this case, $t \mathrm{BHQ}$ was unable to restore the TNF $a$ induced down-regulation of $\gamma \mathrm{GCL}$ activity and GSH levels. In both cases, results shown are the mean \pm SEM and expressed as percentage of control. Statistics: $* * p<0.01$ versus control; $* * * p<0.005$ versus control; $\# p<0.05$ versus control $(\mathrm{n}=4-6)$ 

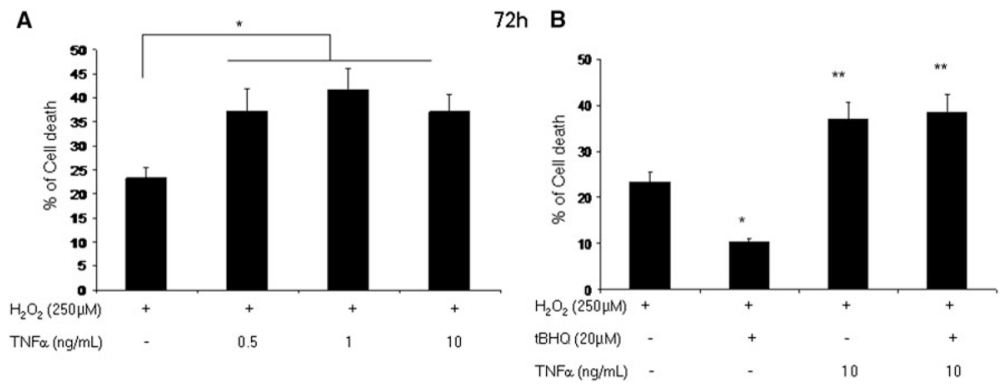

Fig. 5.

TNF $a$ ( $72 \mathrm{~h}$ treatment) increased cell death induced by $3 \mathrm{~h}$ exposure to $250 \mu \mathrm{M}$ hydrogen peroxide. Astrocyte-rich cultures pre-treated for $72 \mathrm{~h}$ with $10 \mathrm{ng} / \mathrm{mL} \mathrm{TNFa}$ showed higher cell death levels when challenged to oxidative stress (a). Treatment with $t \mathrm{BHQ} 20 \mu \mathrm{M}$ was unable to protect from the effects of $72 \mathrm{~h}$ treatment with $10 \mathrm{ng} / \mathrm{mL}$ of TNFa (b). Results are shown as the mean \pm SEM. Statistics: $* p<0.05$ versus control $+\mathrm{H}_{2} \mathrm{O}_{2}$-treatment; $* * p<$ 0.01 versus control $+\mathrm{H}_{2} \mathrm{O}_{2}$-treatment $(\mathrm{n}=4-6)$ 
A
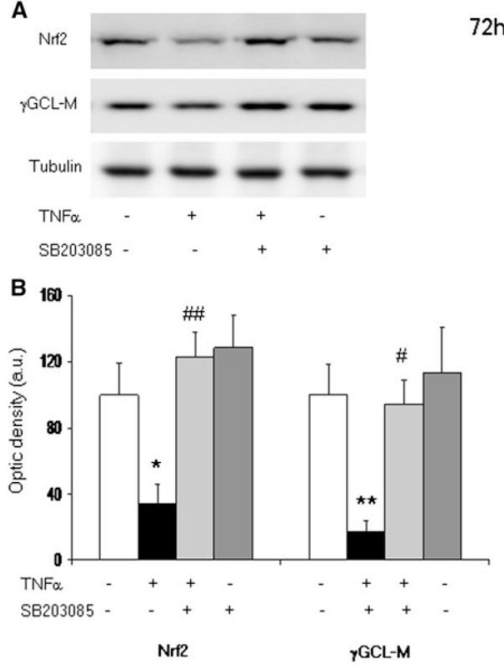

$72 \mathrm{~h}$

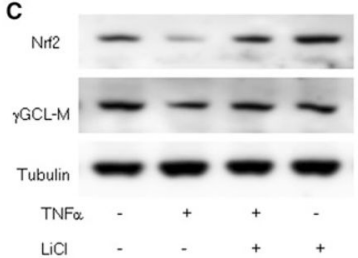

D

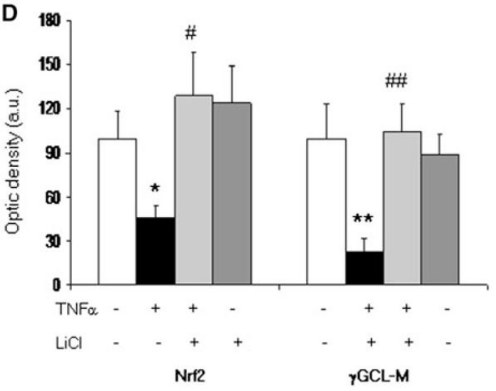

Fig. 6.

Effect of the inhibition of $\mathrm{p} 38 \mathrm{MAPK}$ and GSK $3 \beta$ on the down-regulated expression of Nrf2 and $\gamma \mathrm{GCL}-\mathrm{M}$ induced by $10 \mathrm{ng} / \mathrm{mL}$ of TNF $a(72 \mathrm{~h})$. Inhibition of p38 MAPK activation with the specific inhibitor SB203580 $(20 \mu \mathrm{M})$ resulted in a restoration in the down-regulated expression of Nrf2 and $\gamma$ GCL-M induced by $72 \mathrm{~h}$ treatment with TNF $a(\mathbf{a})$. In (b), the densitometric analysis is shown. Statistics: $* p<0.05$ versus control; $* * p<0.01$ versus control; \#p $<0.05$ versus TNF $a$; \#\# $p<0.01$ versus TNF $a$. Inhibition of GSK3 $\beta$ activation with $\mathrm{LiCl}(5 \mathrm{mM})$ resulted in a reversal of the down-regulated expression of Nrf2 and 2 GCL-M induced by $72 \mathrm{~h}$ treatment with TNF $a(\mathbf{c})$. In (d), the densitometric analysis is shown. Statistics: ${ }^{*} p<0.05$ versus control; $* * p<0.01$ versus control; $\# p<0.05$ versus TNF $a$; \#\# $p<0.01$ versus TNF $a(n=6)$ 